Psychological Reports, 2011, 109, 3, 863-878. C Psychological Reports 2011

\title{
EFFECTS OF DAYLIGHT SAVING TIME CHANGES ON STOCK MARKET VOLATILITY: A REPLY ${ }^{1,2}$
}

\author{
HAKAN BERUMENT \\ Department of Economics \\ Bilkent University
}

\author{
NUKHET DOGAN \\ Department of Econometrics \\ Gazi University
}

\begin{abstract}
Summary.-There is a rich array of evidence that suggests that changes in sleeping patterns affect an individual's decision-making processes. A nationwide sleeping-pattern change happens twice a year when the Daylight Saving Time (DST) change occurs. Kamstra, Kramer, and Levi argued in 2000 that a DST change lowers stock market returns. This study presents evidence that DST changes affect the relationship between stock market return and volatility. Empirical evidence suggests that the positive relationship between return and volatility becomes negative on the Mondays following DST changes.
\end{abstract}

Calendar anomalies in the securities markets are of considerable interest to portfolio managers and investors. Several studies have found that market returns are different on different days of the week, different months of the year, at the turn of the month, and before holidays. Recent studies find evidence of new financial market anomalies for market returns after Daylight Saving Time (DST) changes. According to these studies, change in market participants' behavior is linked to the disruption of sleep patterns (desynchronosis), which decreases returns. Accordingly, Kamstra, Kramer, and Levi (2000) argued that DST-change weekends are followed by large negative and statistically significant returns. They claimed that desynchronosis causes anxiety; because of this anxiety, traders choose safer investments and thus returns decrease. However, Pinegar (2002) questioned the conclusions of Kamstra, et al., arguing that the DST effect is significant only for the fall change and that the effect is caused by outliers associated with major events. Kamstra, Kramer, and Levi (2002) countered this argument based on methodological and international evidence. They showed that the DST effect arises not only due to extreme negative observation in the lower tail, but also because of a lack of positive return observation. On the other hand, Worthington (2003), Lamb, Zuber, and Gandar (2004), and Boido and Fasano (2005) examined the presence of the DST effect in the Australian, U.S., and Italian stock markets, respectively; similar to Pinegar (2002), they could not find statistically significant evidence of the DST effect on returns. Moreover, after studying empiri-

${ }^{1}$ Address correspondence to Hakan Berument, Department of Economics, Bilkent University, 06800 Ankara, Turkey or e-mail (berument@bilkent.edu.tr).

${ }^{2}$ The authors would like to thank Erla Anderson, Mustafa Gultekin, Rana Nelson, and two anonymous referees for their valuable comments. 
cal evidence from 22 stock markets around the world, Gregory-Allen, Jacobsen, and Marquering (2010) could not find statistically significant evidence of a DST anomaly in stock returns. For U.S. markets, Berument, Dogan, and Onar (2008) investigated the possible effect of DST changes on stock market return volatility, as well as on the return itself. They found that DST changes do not affect stock return or volatility.

Not finding statistically significant evidence of lower returns from DST changes by this method does not mean that this effect is not there. There may still be an effect, but it may be occurring for a reason not yet examined. O'Brien and Mindell (2005), Killgore, Balkin, and Wesensten (2006), and Killgore (2007) argued that sleep problems are associated with a higher risk tolerance. The purpose of this study is to provide evidence that lower stock market returns after DST changes are due to a higher risk tolerance (or a lower risk perception) - risk-return relationships change to negative on the dates after the DST changes.

Daylight Saving Time Changes, Return, and Volatility

Sleep is like food for the brain, yet getting enough quality sleep is a problem for many people. The greater part of sleep research suggests that sleep loss or gain is common among shift workers and pilots who suffer from jet lag. Even minor sleep imbalances and disrupted circadian rhythms contribute to judgment errors, processing information less efficiently, and a poorer ability to stay focused on routine tasks (Coren, 1996c). A National Sleep Foundation poll (2001) found that people who suffer from a disruption in their sleep pattern are more impatient or irked and are more likely to make mistakes. Additionally, they suffer more difficulties in making decisions and listening carefully to others. The physiological demands of rotational shift work and jet lag have the potential to affect decision-making ability negatively. Drummond, Gillin, and Brown (2001) suggested that de-synchronosis can increase errors of omission, increase errors of commission, and decrease time spent on a task. Sleep disruption negatively affects a variety of tasks (Moorcroft \& Belcher, 2003), including those that are not routine and for which higher-level cognitive skills are required.

Every spring in April, clocks are moved forward one hour, and in November, clocks are moved back one hour. In most of the U.S., this has been done officially since 1966. Some researchers have found that Daylight Saving Time changes increase traffic accidents. Varughese and Allen (2001) reported a significant increase in crash counts in the U.S. immediately following the shifts to DST in the spring and fall. They argued that these crashes are due to the physiological adjustments and to behavioral responses to "forced changes in the circadian rhythms," as well as to the sleep loss in the springtime. Coren (1996a, 1996b) found a significant in- 
crease in traffic accidents in Canada and in other types of accidents in the U.S. after springtime adjustments, but found no statistically significant effect of the DST changes in the fall on automobile crashes. Other studies, such as Monk (1980) and Hicks, Lindseth, and Hawkins (1983), found increases in traffic accidents following the spring shift to DST, but also failed to find any statistically significant decrease following the fall time change. On the other hand, Ferguson, Preusser, Lund, Zador, and Ulmer (1995), Broughton and Sedman (1989), and Meyerhoff (1978) showed a reduction in road fatalities, specifically for pedestrian crashes, after a DST change. As mentioned above, although some researchers could not find any link, Kamstra, et al. (2000) examined the DST effect on investor behavior. Their empirical evidence suggests that in the U.S., U.K., and Canadian stock markets, DST weekends are typically followed by large negative returns in market indexes, and they are lower than those of regular weekends.

The adverse effects of sleepiness also include problems dealing with unexpected events in which risks need to be realistically assessed. Sleepiness affects various daytime functioning abilities. Clinical and controlled laboratory studies indicate that sleep disturbance is associated with emotional changes and increased risk taking and affects performance of strategic cognitive tasks. O'Brien and Mindell (2005) reported that adolescents with more sleeping problems display significantly more risk-taking behavior and that higher risk-taking behavior increases immediate threats, such as a higher incidence of traffic accidents, unplanned pregnancies, and infectious diseases. Moreover, studying the Iowa Gambling Task, which is thought to simulate real-life decision making, Killgore, et al. (2006) showed that sleep-deprived participants choose higher-risk tasks. By administering the Brief Sensation Seeking Scale, Evaluation of Risks Scale, and Balloon Analog Risk Task Scales, Killgore (2007) reported that sleep disturbances produce changes in risk-taking and sensation-seeking tasks. Brown, Tickner, and Simmonds (1970) showed that sleep deprivation due to extended driving increases risky decisions, such as passing with low visibility or forcing other drivers to adjust their speed to permit the tired driver to pass.

A significant academic tradition links stock market return with risk. To communicate price behaviors in a simple theoretical model, Merton's capital asset pricing model (1973) showed that the conditional excess market return is a linear function of its conditional variance (the risk component) and its covariance with investment opportunities (the hedge component). In a later study, Merton (1980) argued that under certain conditions, the conditional market return is proportional to its conditional variance, and the hedge component is negligible. Capital asset pricing models as 
developed by Markowitz (1952), Sharpe (1964), Lintner (1965), and Mossin (1966) assumed an efficient capital market. According to these models, if investors are risk averse, they have the same expectations of stock performances and earnings, and then the relationship between return and variance or risk should be positive. Conversely, if investors are risk lovers, they will prefer risky portfolios, with the expectation of extra returns, and then the relationship should be negative.

Fama and MacBeth (1973) examined the relationship between average return and risk for the New York Stock Exchange (NYSE). They could not reject the hypothesis that the pricing of common stocks reflects the attempts of risk-averse investors to hold portfolios that are "efficient" in terms of expected value and dispersion of returns. Jacob (1971) examined the efficient market hypothesis for the NYSE, and the results showed a significant positive relationship between realized return and risk. Jensen, Black, and Scholes' evidence (1972), which is based on an asset pricing model, indicated the existence of a positive linear relationship between risk and return for the NYSE. More recent studies promote the appropriateness of using conditional variance models such as ARCH and GARCH processes to proxy for risk, such as French, Schwert, and Stambaugh (1987), Connolly (1989), Baillie and DeGennaro (1990), and Berument and Kiymaz (2001).

The purpose of this paper is to assess whether there exists a relationship between return and risk (when risk is measured with volatility) with DST changes. If disruption of sleep is associated with risk-taking behavior, then if people take risks after DST changes and if risk is linked to return, the risk-return relationship with DST changes should change.

\section{DATA}

In this study, in order to be able to match and compare results, the authors chose the same indexes as Kamstra, et al. (2000), which have the largest and most liquid stocks in the markets: the NYSE, the Standard \& Poor's 500 (S\&P500), the National Association of Securities Dealers Automated Quotations (NASDAQ), and the American Stock Exchange (AMEX). The data consist of both equal- and value-weighted daily indexes and are collected from the Center for Research in Security Prices (CRSP). The data span for the NYSE, S\&P500, and AMEX indexes starts from January 3, 1967, and the NASDAQ index starts from December 15, 1972. The data span for all indexes ends on June 29, 2007.

These indexes play central roles in stock market performance measures, are continuously covered by major media, and consistently attract attention from investors, academic researchers, and policy makers. Blume and Stambaugh (1983), Brennan and Schwartz (1985), and Canina, Michaely, Thaler, and Womack (1998) found systematic differences between 
equal-weighted portfolios and value-weighted portfolios. In order to address this, the present authors used equal- and value-weighted indexes.

Daylight Saving Time has been used in some parts of the U.S. since World War I, and its use gradually increased. In the early 1960s, the observance of DST was quite inconsistent, with no agreement about when to change clocks. By 1966, Congress decided to step in and end the confusion by establishing one pattern across the country. For that reason, the data span starts in 1967. Until 1986, Daylight Saving Time began on the last Sunday of April and ended on the last Sunday of October. U.S. law was amended in 1986 to begin DST on the first Sunday in April. Then, beginning in 2007, most of the United States began DST on the second Sunday in March and reverted to standard time on the first Sunday in November. There were no time changes in the year $1974 .{ }^{3}$ After analyzing the information, the dummy variable for DST was used for the first business day after the DST change and values of one and zero were assigned otherwise for analyses.

In Table 1, the mean from the daily return data was calculated. This gives the expected returns of the four series (NYSE, S\&P500, NASDAQ, and AMEX) for their equal- and value-weighted indexes for Mondays, DST (Mondays with DST changes in both spring and fall), DST Spring (Mondays with DST changes in the spring, when one hour is lost), and DST Fall (Mondays with daylight saving change in the fall, when one hour is gained). The expected returns of Mondays are always negative, while on "Other Days," expected returns are positive for all indexes. The mean DST, DST Spring, and DST Fall Mondays are always negative and smaller than the mean regular Mondays for every index. When DST changes in spring and fall are compared, the mean returns are more strongly negative in the fall. Table 2 reports the variances of the daily returns for all indexes. Among DST, DST Spring, DST Fall, and Mondays, the highest volatilities are observed for DST Fall. On the other hand, regular Monday volatilities are always higher than the Other Days' volatilities for all indexes.

Model and Estimates

In this paper, to examine the effect of DST changes on the return-volatility relationship, a version of Nelson's Exponential Generalized Autoregressive Conditional Heteroskedastic (EGARCH; 1991) model for volatility was considered. EGARCH models do not require non-negative constraints for estimated parameters, and the model allows for the asymmetry of news or shocks on the conditional variance, $h_{t}^{2}$. To estimate the DST effect in the return equation, $R$, one could estimate the model such that, first, $h_{t}^{2}$ could be generated from a separate specification and, next,

${ }^{3}$ The United States Naval Observatory: http://aa.usno.navy.mil/faq/docs/daylight_time.php and web exhibits: http://www.webexhibits.org/daylightsaving/e.html. 


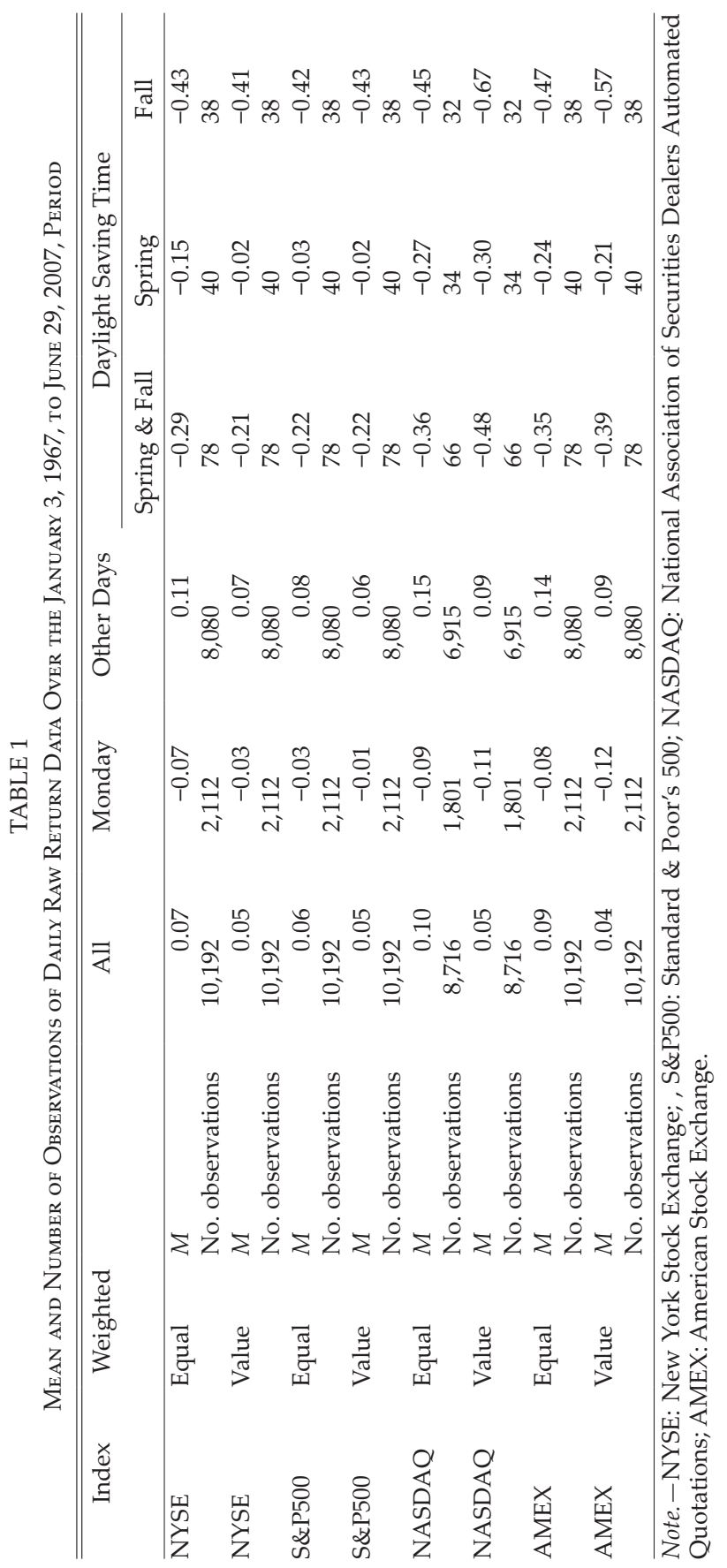


TABLE 2

Variance of Daily Raw Return Data over the January 3, 1967, to June 29, 2007, Period

\begin{tabular}{llllllll}
\hline \hline Index & Weighted & All & Monday & $\begin{array}{c}\text { Other } \\
\text { Days }\end{array}$ & & & \multicolumn{3}{c}{ Daylight Saving Time } \\
\cline { 6 - 8 } & & & & & $\begin{array}{c}\text { Spring \& } \\
\text { Fall }\end{array}$ & Spring & Fall \\
\hline NYSE & Equal & 0.57 & 0.79 & 0.51 & 1.68 & 0.51 & 2.91 \\
NYSE & Value & 0.77 & 1.06 & 0.70 & 1.91 & 0.60 & 3.25 \\
S\&P500 & Equal & 0.86 & 1.18 & 0.78 & 2.26 & 0.63 & 3.96 \\
S\&P500 & Value & 0.91 & 1.22 & 0.83 & 2.04 & 0.64 & 3.48 \\
NASDAQ & Equal & 0.57 & 0.69 & 0.52 & 2.01 & 0.97 & 3.16 \\
NASDAQ & Value & 1.46 & 1.69 & 1.39 & 3.92 & 2.76 & 5.20 \\
AMEX & Equal & 0.57 & 0.75 & 0.52 & 1.71 & 0.63 & 2.88 \\
AMEX & Value & 0.77 & 0.97 & 0.71 & 2.11 & 0.86 & 3.41 \\
\hline
\end{tabular}

Note.-NYSE: New York Stock Exchange; S\&P500: Standard \& Poor's 500; NASDAQ: National Association of Securities Dealers Automated Quotations; AMEX: American Stock Exchange.

this volatility measure could be used as a regressor in the return equation. Pagan (1984) argued that following this method (a generated regressor model) leads to biased estimators. Pagan and Ullah (1988) suggested using the Full Information Maximum Likelihood method to estimate parameters. However, following Bollerslev and Wooldridge (1992), the present authors used the Quasi-Maximum Likelihood method (QMLE) to estimate the parameters. ${ }^{4}$ The return equation estimated is the following:

$$
R_{t}=\alpha_{0}+\alpha_{M} M_{t}+\alpha_{D S T} D S T_{t}+\sum_{i=1}^{n} \alpha_{i} R_{t-i}+\lambda h_{t}^{2}+\lambda_{M} M_{t} h_{t}^{2}+\lambda_{D S T} D S T_{t} h_{t}^{2}+\varepsilon_{t},
$$

where $M_{t}$ and $D S T_{t}$ are dummy variables for Monday and the DST change in fall and spring at time $t$. In previous research, as in Cross (1973), French (1980), and Gibbons and Hess (1981), the present authors modeled the return using daily dummies. In order to see the difference between Mondays following DST changes and regular Mondays, both dummy variables were included. The lag values of the return variable, $R_{t-i^{\prime}}$ are included in the equation to eliminate the autocorrelated residual problem. ${ }^{5} \mathrm{~A}$ changing return-volatility relationship for regular Monday and DST changes in spring and fall is allowed, and the interactive dummy variables (obtained by multiplying the Monday and DST dummy variables with the conditional variance) are incorporated into the specification. Furthermore, the

${ }^{4}$ Bollerslev and Wooldridge (1992) argued that the normality of the standardized conditional errors ${ }^{\varepsilon_{t}} / h_{t}$ assumption may cause misspecification of the likelihood function. Therefore, they suggest using the QMLE method to avoid this problem. Bollerslev and Wooldridge formally show that the QMLE is generally consistent and has a limited distribution.

${ }^{5}$ Jansen and Cosimona (1988) argued that even if the ARCH effect does not exist, autocorrelated errors indicate (wrongly) an ARCH effect. The optimum lag length was determined with Final Prediction Error (FPE) criteria, which determined the lag length such that errors are no longer autocorrelated. 
conditional variance $h_{t}^{2}$ is used as a measure of volatility in Equation [1]. The time-varying variance is modeled using the EGARCH process:

$$
\log h_{t}^{2}=\kappa+\sum_{i=1}^{v} \delta_{i} \log h_{t-i}^{2}+\gamma_{1}\left(\left|\frac{\varepsilon_{t-1}}{h_{t-1}}\right|-E\left|\frac{\varepsilon_{t-1}}{h_{t-1}}\right|+\chi \frac{\varepsilon_{t-1}}{h_{t-1}}\right),
$$

for $\varepsilon_{\mathrm{t}}$ follows the General Error Distribution (GED) and consequently,

$$
E\left|\frac{\varepsilon_{t}}{h_{t}}\right|=\Lambda 2^{\frac{1}{D}} \frac{\Gamma\left(\frac{2}{D}\right)}{\Gamma\left(\frac{1}{D}\right)},
$$

where $\Gamma($.$) is the gamma function,$

$$
\Lambda=\sqrt{2^{\frac{-2}{D}} \frac{\Gamma\left(\frac{1}{D}\right)}{\Gamma\left(\frac{3}{D}\right)},}
$$

and $\mathrm{D}$ is the parameter for the GED. ${ }^{6}$

The EGARCH model also allows for different effects of shocks on volatility - the leverage effect. The parameter $\chi$ captures the leverage effect. If $\chi=0, \log h_{t}^{2}$ responds symmetrically to innovations. If $-1<\chi<0$, negative surprises increase volatility more than positive surprises do; if $\chi<-1$, then positive surprises reduce volatility while negative surprises increase volatility. Furthermore, to produce the leverage effect, $\chi$ must be negative.

The EGARCH specification estimates of Equations [1] and [2], corresponding to each of the equal- and value-weighted indexes, are given in Table 3.7 Panel A reports the estimates of the return equation and Panel B reports the estimates of the conditional variance specification. Moreover, Panels $C$ and D show the $p$ values of the robustness test statistics and a set of non-parametric tests, respectively. $M_{t}$ and $D S T_{t}$ are the dummy variables for regular Mondays and Mondays after the DST changes in both spring and fall at time $t$. Moreover, $R_{t-i}, h_{t}^{2}$, and $\chi$ indicate the parameters for the lagged returns, the conditional variance of the returns, and the leverage effect, respectively. Based on the estimates of the return specification, it was observed that the coefficients of Monday dummy variables are

${ }^{6}$ The GED is a class of distributions where the Normal and $t$ distributions are special cases. D is a positive parameter governing the thickness of the tails; if $\mathrm{D}=2$, the distribution is normal; if $\mathrm{D}<2$, the density has thicker tails than the normal distribution; and if $\mathrm{D}>2$, the density has thinner tails.

${ }^{7}$ The EGARCH specification is a highly non-linear system and, thus, estimates might be sensitive to initial values and maximization algorithms. The data set used in this study and computer codes are available from http://www.bilkent.edu.tr/ berument/PR01.rar; http://www. bilkent.edu.tr/ berument/PR02.rar; and http://www.bilkent.edu.tr/ berument/PR03.rar. 
negative and statistically significant for all indexes. This finding parallels the findings by Osborne (1962), Cross (1973), French (1980), Gibbons and Hess (1981), Jaffe, Westerfield, and Ma (1989), Chang, Pinegar, and Ravichandran (1993), Agrawal and Tandon (1994), and Dubois and Louvet (1996). On the other hand, the estimated coefficients of DST are all positive but statistically significant only for the equally weighted S\&P500 Index. This result is the reverse of that of Kamstra, et al. (2000), who found a negative DST effect on return. A possible reason for this reverse result might be that in Kamstra, et al., the mean specification does not include volatility measures. On the other hand, French and Roll (1986) and Berument and Kiymaz (2001) claimed that volatility increases on Monday, thereby, in Kamstra, et al., the mean equation DST coefficient is negative. The mean equation in the present study also captures volatility, and this might be the reason for finding positive DST coefficients.

The estimates of the coefficient $h_{t}^{2}$ are always positive and statistically significant for all indexes. This is similar to the evidence reported by Scruggs (1998), Bali and Peng (2006), and Ghysels, Clara, and Valkanov (2005). They suggest that if the coefficient of conditional variance in the mean equation is positive, it means that high (low) volatility is associated with high (low) returns. The estimated coefficients of the interactive Monday dummy variable with $h_{t}^{2}$ are negative except for the equal- and valueweighted S\&P500 and value-weighted NASDAQ indexes, which are not statistically significant. ${ }^{8}$ Furthermore, negative interactive Monday coefficients are statistically significant for the equal-weighted NYSE and NASDAQ indexes at the $1 \%$ and $10 \%$ level, and both equal- and value-weighted AMEX indexes at the $1 \%$ level.

Importantly, the interactive DST dummy variables with the volatility measure are all negative. This supports the proposition that DST changes increase risk appetite but that this effect is statistically significant only for the value-weighted NYSE and the S\&P500 indexes, and the equal-weighted NASDAQ index at the 5\% level; and for the value-weighted NASDAQ and AMEX indexes at the $10 \%$ level. The last row of Panel A reports the total effect for the DST change days. The estimated coefficients for the DST, $\lambda+\lambda_{M}+\lambda_{D S T^{\prime}}$ are always negative and statistically significant at the $10 \%$ level for five of the eight indexes considered. Thus, the return-volatility relationship changes on the dates of the DST changes, ${ }^{9}$ and therefore, the

${ }^{8}$ The level of significance is $5 \%$, unless otherwise noted.

${ }^{9}$ Pinegar (2002) questions the conclusions of Kamstra, et al. (2000), arguing that the DST effect is significant only for the fall change but that effect is caused by outliers associated with major events. To address this, the same model was estimated with an outlier robust method developed by Carnero, Pena, and Ruiz (2007). Franses and Ghijsels' method (1999) was also used to detect and address outliers for a subset of indexes. The present results are robust. These estimates are not reported here but are available from the authors upon request. 
unbiased and maybe less-efficient model may be due to over-parameterization. This may reaffirm the evidence of a daylight savings effect on returns; however, the DST effect works through lower risk tolerance.

In Panel B of Table 3, the estimates on the conditional variance specification are reported. The authors specify the logarithm of the conditional variance such that standardized residuals are no longer autocorrelated or are not heteroskedastic. The characteristic roots of the polynomials are all inside the unit circle, so the conditional variance specification is not explosive (see Nelson, 1991). The estimated coefficient for $\chi$ is always negative and statistically significant at the $1 \%$ level for all the indexes considered. This finding is consistent with the leverage hypothesis: negative surprises increase volatility more than positive surprises, which parallel many previous works, such as Cheung and $\mathrm{Ng}$ (1992) and Kim and Kon (1994). Harvey and Shephard (1996) and Yu (2005) point out that if $\chi$ is different than zero, the market does not comply to the standard efficient market hypothesis, and it is plausible that investors' behaviors are somewhat driven by emotional factors. This is also in line with the DST effect on the relationship between stock market return and volatility.

The presence of autocorrelation and the ARCH effect was tested, and the $p$ values of three sets of robustness test statistics were reorted; the first part of Panel C reports the Ljung-Box Q-statistics for the standardized residuals; the second part, the squared standardized residuals; and the last, the Lagrange Multiplier (LM) test for the 5, 10, 20, and 60 lags. As for the results of the Ljung-Box Q-statistics, we can reject the null hypothesis that standardized residuals are not autocorrelated for equally weighted NYSE indexes for 60 lags at 5\%, equally weighted NASDAQ indexes for 5 and 20 lags at $10 \%$, and 60 lags at 1\%, and equally weighted AMEX indexes for 5,20 , and 60 lags at $1 \%$ and 10 lags at $10 \%$. The second set of statistics gives the Ljung-Box Q-statistics for the squared standardized residuals. The null hypothesis that the squared normalized residuals are not autocorrelated can only be rejected for the equally weighted S\&P500 and both weighted NASDAQ indexes for 60 lags. The third set performs the ARCHLM test for the standardized residuals for the 5, 10, 20, and 60 lags. There is no statistically significant ARCH effect in the standardized residuals except for the value-weighted NYSE index at 10\%, both weighted S\&P500 indexes at 5 and $10 \%$ for 60 lags, the equally weighted NASDAQ index for 5 lags at $10 \%$ and 60 lags at 5\%, the value-weighted NASDAQ index for all lags at $1 \%$, and both weighted AMEX indexes for 5 and 10 lags at $5 \%$.

A set of non-parametric sign- and size-biased tests provided in Panel D of Table 3. We cannot reject the null hypothesis that standardized residuals are not systematic (see Berument, Coskun, \& Sahir, 2007, for details) for any of the indexes when we employ sign and negative-size tests; for equal- and value-weighted AMEX indexes when we employ positive- 
DAYLIGHT SAVING TIME AND STOCK MARKET VOLATILITY

TABLE 3

Daylight Saving Time Effect on Return-volatility Relationships Over the January 3, 1967, to June 29, 2007, Period

\begin{tabular}{|c|c|c|c|c|c|c|c|c|}
\hline & \multicolumn{2}{|c|}{ NYSE } & \multicolumn{2}{|c|}{ S\&P500 } & \multicolumn{2}{|c|}{ NASDAQ } & \multicolumn{2}{|c|}{ AMEX } \\
\hline & Equal & Value & Equal & Value & Equal & Value & Equal & Value \\
\hline \multicolumn{9}{|c|}{ Panel A: Return Specification } \\
\hline Constant & $0.03 \neq$ & $0.04 \neq$ & $0.04 \neq$ & $0.03 \neq$ & $0.07 \neq$ & $0.08 \neq$ & $0.04 \neq$ & $0.04 \neq$ \\
\hline$t$ & 3.08 & 2.83 & 3.38 & 2.52 & 9.76 & 7.05 & 4.53 & 3.17 \\
\hline$M_{t}$ & $-0.09 \neq$ & $-0.06 \neq$ & $-0.11 \neq$ & $-0.07 \neq$ & $-0.24 \neq$ & $-0.22 \neq$ & $-0.16 \neq$ & $-0.09 \neq$ \\
\hline$t$ & -4.34 & -2.17 & -4.24 & -2.51 & -18.17 & -10.29 & -8.76 & -4.36 \\
\hline $\mathrm{DST}_{\mathrm{t}}$ & 0.06 & 0.16 & $0.19+$ & 0.19 & 0.03 & 0.07 & 0.003 & 0.11 \\
\hline$t$ & 0.69 & 1.35 & 1.78 & 1.46 & 0.51 & 0.69 & 0.04 & 1.08 \\
\hline$R_{t-1}$ & $0.31 \neq$ & $0.15 \neq$ & $0.19 \neq$ & $0.10 \neq$ & $0.38 \neq$ & 0.23 & $0.35 \neq$ & 0.27 \\
\hline${ }^{t-1} t$ & 30.23 & 14.74 & 18.15 & 10.28 & 34.40 & 21.43 & 34.69 & 26.31 \\
\hline$R_{t-2}$ & $-0.02^{*}$ & $-0.02 \dagger$ & -0.01 & $-0.02 \dagger$ & -0.01 & $-0.02 \dagger$ & 0.01 & $-0.02 \dagger$ \\
\hline${ }_{t-2}^{t-2}$ & -1.79 & -2.19 & -0.97 & -1.94 & -1.15 & -2.22 & 0.67 & -2.33 \\
\hline$R_{t-3}$ & $0.07 \neq$ & 0.01 & $0.03 \dagger$ & & $0.08 \neq$ & $0.04 \neq$ & $0.08 \neq$ & $0.06 \neq$ \\
\hline$t$ & 6.71 & 0.48 & 2.49 & & 7.22 & 3.86 & 7.98 & 5.39 \\
\hline$R_{t-4}$ & $0.03 \neq$ & & $0.02 \dagger$ & & $0.04 \neq$ & $0.02 \dagger$ & $0.04 \neq$ & $0.02 \dagger$ \\
\hline${ }^{t-4}$ & 2.83 & & 2.36 & & 3.69 & 2.05 & 3.95 & 1.91 \\
\hline$R_{t-5}$ & $0.03 \neq$ & & & & $0.05 \neq$ & $0.02 \dagger$ & $0.04 \neq$ & $0.03 \neq$ \\
\hline${ }^{t=3}$ & 2.94 & & & & 4.82 & 1.97 & 4.40 & 3.05 \\
\hline$R_{t-6}$ & 0.0001 & & & & $0.04 \neq$ & 0.01 & 0.01 & -0.001 \\
\hline$t$ & 0.01 & & & & 3.341 & 0.416 & 1.205 & -0.090 \\
\hline$R_{t-7}$ & 0.01 & & & & -0.01 & -0.01 & 0.01 & 0.01 \\
\hline${ }_{t}^{t-7} t$ & 1.16 & & & & -1.20 & -0.45 & 0.58 & 0.50 \\
\hline$R_{t-8}$ & $0.02 \dagger$ & & & & 0.02 & 0.01 & 0.01 & 0.01 \\
\hline$t$ & 1.96 & & & & 1.43 & 0.59 & 1.24 & 1.02 \\
\hline$R_{t-9}$ & 0.002 & & & & 0.01 & 0.01 & 0.001 & 0.0002 \\
\hline$t$ & 0.16 & & & & 1.17 & 0.70 & 0.09 & 0.03 \\
\hline$R_{t-10}$ & $0.02 \dagger$ & & & & $0.05 \neq$ & $0.03 \neq$ & $0.03 \neq$ & $0.02 \dagger$ \\
\hline$\stackrel{t-10}{t}$ & 2.29 & & & & 4.76 & 2.59 & 3.45 & 2.28 \\
\hline$R_{t-11}$ & 0.01 & & & & $0.03 \neq$ & 0.01 & 0.01 & -0.004 \\
\hline$t$ & 1.12 & & & & 2.47 & 1.13 & 0.79 & -0.41 \\
\hline$R_{t-12}$ & $0.03 \neq$ & & & & $0.02 \dagger$ & $0.04 \neq$ & 0.004 & $0.02^{*}$ \\
\hline$\stackrel{t-12}{t}$ & 3.43 & & & & 2.18 & 3.94 & 0.43 & 1.78 \\
\hline$R_{t-13}$ & & & & & -0.01 & $0.02 \dagger$ & 0.01 & 0.01 \\
\hline$t$ & & & & & -0.77 & 2.14 & 0.59 & 1.20 \\
\hline$R_{t-14}$ & & & & & $0.02 \neq$ & 0.02 & 0.004 & $0.02 \dagger$ \\
\hline${ }_{t}^{t-14}$ & & & & & 2.45 & 1.61 & 0.50 & 2.07 \\
\hline$R_{t-15}$ & & & & & $0.04 \neq$ & $0.02^{*}$ & $0.04 \neq$ & 0.01 \\
\hline $\begin{array}{c}t-15 \\
t\end{array}$ & & & & & 3.90 & 1.84 & 4.84 & 1.33 \\
\hline$M_{t} h_{t}^{2}$ & $-0.25 \neq$ & -0.03 & 0.02 & 0.02 & $-0.08^{*}$ & 0.02 & $-0.28 \neq$ & $-0.19 \neq$ \\
\hline$t^{t}$ & -4.46 & -0.60 & 0.43 & 0.50 & -1.81 & 0.90 & -4.95 & -4.37 \\
\hline $\operatorname{DST}_{t} h_{t}^{2}$ & -0.24 & $-0.34 \dagger$ & $-0.34 \dagger$ & $-0.35 \dagger$ & $-0.27 \dagger$ & $-0.17^{*}$ & -0.14 & $-0.28^{*}$ \\
\hline$t^{t+t}$ & -1.25 & -1.98 & -2.38 & -2.15 & -1.98 & -1.90 & -0.78 & -1.67 \\
\hline \multicolumn{9}{|c|}{ (continued on next page) } \\
\hline
\end{tabular}

Note.-NYSE: New York Stock Exchange; S\&P500: Standard \& Poor's 500; NASDAQ: National Association of Securities Dealers Automated Quotations; AMEX: American Stock Exchange. ${ }^{*}$ Level of significance at $10 \%$. †Level of significance at $5 \%$. $\neq$ Level of significance at $1 \%$. 
TABLE 3 (CONT'D)

Daylight Saving Time Effect on Return-volatility Relationships Over the January 03, 1967, to June 29, 2007, Period

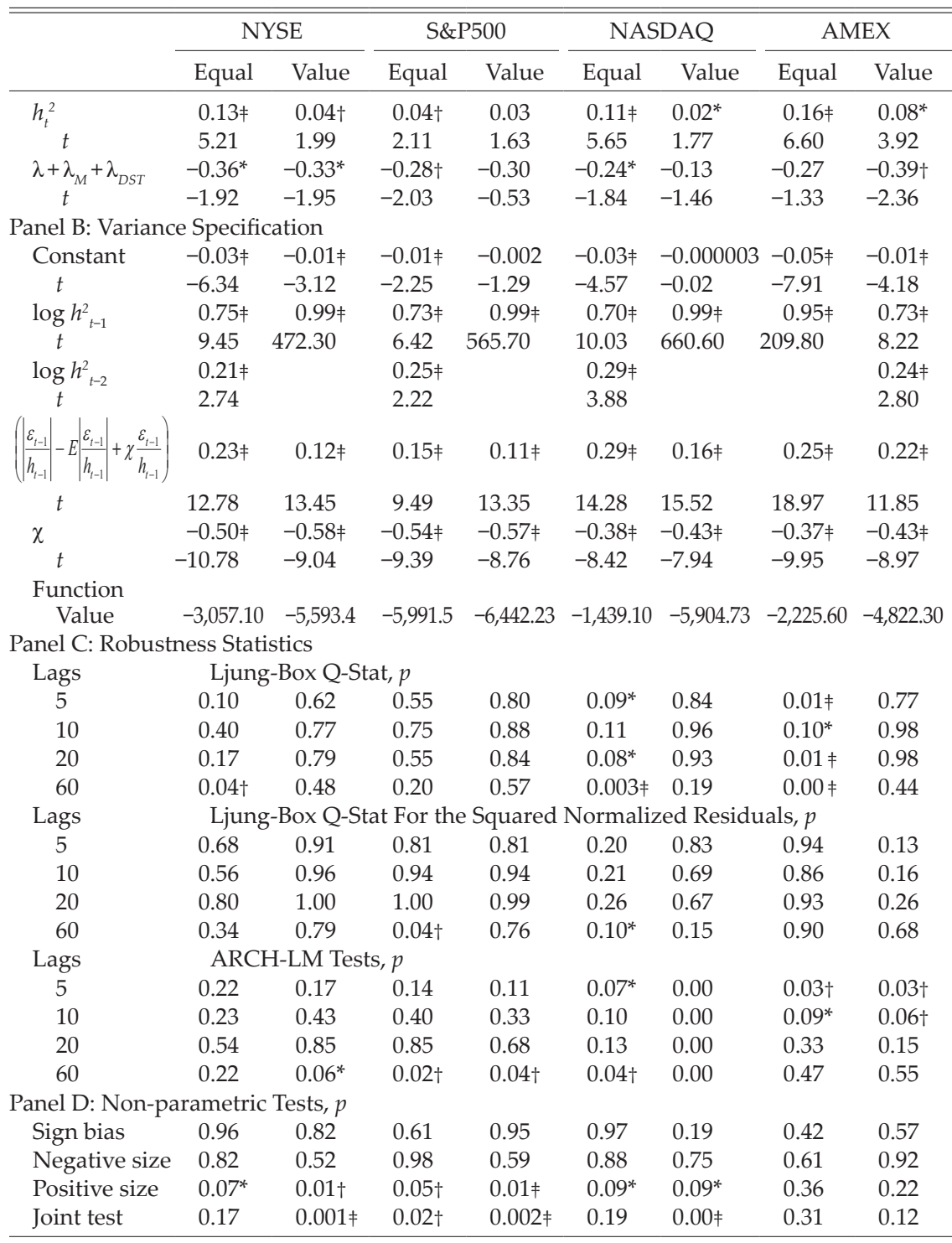

Note.-NYSE: New York Stock Exchange; S\&P500: Standard \& Poor's 500; NASDAQ: National Association of Securities Dealers Automated Quotations; AMEX: American Stock Exchange. ${ }^{*}$ Level of significance at $10 \%$. + Level of significance at $5 \%$. $\neq$ Level of significance at $1 \%$. 
size and joint tests; and for equal-weighted indexes of NYSE and NASDAQ when we employ joint tests. $R^{2} s$ are not useful in the EGARCH specification because the left-hand-side variable is weighted with conditional standard errors (one may look at any basic econometrics textbook, such as Wooldridge, 2009, p. 278 for clarification). As none of the influential $\mathrm{ARCH}$ articles collected in Engle's seminal book (1995) report them, $R^{2} \mathrm{~s}$ are not reported here.

\section{Conclusion}

Kamstra, et al. (2000) argued that Daylight Saving Time changes are associated with lower returns. Although subsequent studies such as Pinegar (2002) could not confirm the DST effect, the present study examines DST changes within a return-volatility relationship. The present estimates allow a time-varying risk term and find that the effect of DST is more pronounced during volatile periods. Thus, the DST effect is observed even after accounting for the two outliers that Pinegar (2002) mentioned, and it works through lower risk pricing. The present study reports empirical evidence from equal- and value-weighted NYSE, S\&P500, NASDAQ, and AMEX index returns on DST changes and argues that the lower return on DST is due to lower pricing of the volatility on DST changes. This parallels the existing psychological literature, which suggests that sleeping imbalances increase risk tolerance. This effect is statistically significant at the $10 \%$ level for all the indexes considered here, except the equal-weighted indexes for NYSE and AMEX.

\section{REFERENCES}

Agrawal, A., \& Tandon, K. (1994) Anomalies or illusions? Evidence from stock markets in eighteen countries. Journal of International Money and Finance, 13, 83-106.

Baillie, R. T., \& DeGennaro, R. P. (1990) Stock return and volatility. Journal of Financial and Quantitative Analysis, 25, 203-214.

BALI, T. G., \& PENG, L. (2006) Is there a risk-return tradeoff? Evidence from high-frequency data. Journal of Applied Econometrics, 21, 1169-1198.

Berument, H., Coskun, M. N., \& Sahin, A. (2007) Day of the week effect on foreign exchange market volatility: evidence from Turkey. Research in International Business and Finance, 21, 87-97.

Berument, H., Dogan, N., \& Onar, B. (2008) The effects of daylight saving time changes on stock market volatility. Retrieved from Social Science Research Network: http: //ssrn.com/abstract $=1137082$.

Berument, H., \& Kiymaz, H. (2001) The day of the week effect on stock market volatility. Journal of Economics and Finance, 25, 181-193.

Blume, M., \& Stambaugh, R. F. (1983) Biases in computed returns: an application to the size effect. Journal of Financial Economics, 12, 357-369.

Boido, C., \& Fasano, A. (2005) Calendar anomalies: Daylight Savings effects. Paper presented at the 2005 FMA European Conference, Siena, Italy. 
Bollerslev, T., \& Wooldridge, J. M. (1992) Quasi-maximum likelihood estimation and inference in dynamic models with time-varying covariances. Econometric Reviews, 11, 143-172.

Brennan, M. J., \& Schwartz, E. S. (1985) On the geometric mean index: a note. Journal of Financial and Quantitative Analysis, 20, 119-122.

Broughton, J., \& Sedman, R. J. (1989) The potential effects on road casualties of double British summer time. Research Report 228, UK Transport and Road Research Laboratory.

Brown, I. D., Tickner, A. H., \& Simmonds, D. C. V. (1970) The effect of prolonged driving on overtaking criteria. Ergonomics, 13, 239-242.

Canina, L., Michaely, R., Thaler, R., \& Womack, K. (1998) Caveat compounder: a warning about using the daily CRSP Equal-Weighted Index to compute long-run excess returns. Journal of Finance, 53, 403-416.

Carnero, M., Pena, D., \& Ruiz, E. (2007) Effects of outliers on the identification and estimation of GARCH models. Journal of Time Series Analysis, 28, 471-497.

Chang, E., Pinegar, M. J., \& Ravichandran, R. (1993) International evidence on the robustness of the day-of-the-week effect. Journal of Financial and Quantitative Analysis, 28, 497-513.

Cheung, Y., \& NG, L. K. (1992) Stock price dynamics and firm size: an empirical investigation. Journal of Finance, 47, 1985-1997.

Connolly, R. A. (1989) An examination of the robustness of the weekend effect. Journal of Financial and Quantitative Analysis, 24, 133-169.

Coren, S. (1996a) Accidental death and the shift to Daylight Savings Time. Perceptual and Motor Skills, 83, 921-922.

Coren, S. (1996b) Daylight Savings Time and traffic accidents. The New England Journal of Medicine, 334, 924-925.

Coren, S. (1996c) Sleep thieves. New York: The Free Press.

Cross, F. (1973) The behavior of stock prices on Friday and Monday. Financial Analysts Journal, 29(6), 67-69.

Drummond, S. P. A., Gillin, J. C., \& Brown, G. G. (2001) Increased cerebral response during a divided attention task following sleep deprivation. Journal of Sleep Research, 10(2), 85-92.

Dubois, M., \& Louvet, P. (1996) The day-of-the-week effect: international evidence. Journal of Banking and Finance, 20, 1463-1484.

EngLE, R. (1995) ARCH selected readings. Oxford, UK: Oxford Univer. Press.

FAMA, E. F., \& MACBETH, J. D. (1973) Risk, return and equilibrium. Journal of Political Economy, 1, 607-636.

Ferguson, S. A., Preusser, D. F., Lund, A. K., Zador, P. L., \& Ulmer, R. G. (1995) Daylight Saving Time and motor vehicle crashes: the reduction in pedestrian and vehicle occupant fatalities. American Journal of Public Health, 85, 92-95.

Franses, P. H., \& Ghijsels, H. (1999) Additive outliers, GARCH, and forecasting volatility. International Journal of Forecasting, 15, 1-9.

FRENCH, K. R. (1980) Stock returns and the weekend effect. Journal of Financial Economics, 8, 55-69.

FRENCH, K. R., \& RolL, R. (1986) Stock return variances: the arrival of information and the reaction of traders. Journal of Financial Economics, 17(1), 5-26. 
French, K. R., Schwert, G. W., \& Stambaugh, R. E. (1987) Expected stock returns and volatility. Journal of Financial Economics, 19, 3-29.

Ghysels, E., Clara, P. S., \& Valkanov, R. (2005) There is a risk-return tradeoff after all. Journal of Financial Economics, 76, 509-548.

Gibbons, M. R., \& Hess, P. (1981) Day-of-the-week effect and asset returns. The Journal of Business, 54, 579-596.

Gregory-Allen, R., Jacobsen, B., \& Marquering, W. (2010) The Daylight Saving Time anomaly in stock returns: fact or fiction? Journal of Financial Research, 33, 403-427.

HARveY, A. C., \& ShePHARD, N. (1996) Estimation of an asymmetric stochastic volatility model for asset returns. Journal of Business \& Economic Statistics, 14, 429-434.

Hicks, R. A., Lindseth, K., \& Hawkins, J. (1983) Daylight Saving-time changes increase traffic accidents. Perceptual and Motor Skills, 56, 64-66.

ЈАсов, N. (1971) The measurement of systematic risk for securities and portfolios: some empirical results. Journal of Financial and Quantitative Analysis, 6, 815-833.

JAfFe, J., Westerfield, R., \& MA, C. (1989) A twist on the Monday effect in stock prices: evidence from the U.S. and foreign stock markets. Journal of Banking and Finance, 13, 641-650.

Jansen, D. W., \& Cosimona, T. F. (1988) Estimates of the variance of U.S. inflation based upon the ARCH model: a comment. Journal of Money, Credit and Banking, 20, 409-421.

Jensen, M. C., Black, F., \& Scholes, M. (1972) The capital asset pricing model: some empirical tests. In M. Jensen (Ed.), Studies in the theory of capital markets. New York: Praeger. Pp. 79-121.

Kamstra, M. J., Kramer, L. A., \& Levi, D. M. (2000) Losing sleep at the market: the Daylight-Savings anomaly. American Economic Review, 90, 1005-1011.

Kamstra, M. J., Kramer, L. A., \& Levi, D. M. (2002) Losing sleep at the market: the Daylight-Savings anomaly: reply. American Economic Review, 92, 1257-1263.

Killgore, W. D. (2007) Effects of sleep deprivation and morningness-eveningness traits on risk-taking. Psychological Reports, 100, 613-626.

Killgore, W. D. S., Balkin, T. J., \& Wesensten, N. J. (2006) Impaired decision-making following $49 \mathrm{~h}$ of sleep deprivation. Journal of Sleep Research, 15, 7-13.

KIM, D., \& Kon, S. J. (1994) Alternative models for the conditional heteroscedasticity of stock returns. The Journal of Business, 67, 563-598.

Lamb, R. P., Zuber, R. A., \& Gandar, J. M. (2004) Don't lose sleep on it: re-examination of the Daylight Savings anomaly. Applied Financial Economics, 14, 443-446.

LinTNER, J. (1965) Security prices, risk, and maximum gains from diversification. Journal of Finance, 20, 587-615.

Markowitz, H. (1952) Portfolio selection. The Journal of Finance, 12, 77-91.

Merton, R. C. (1973) An intertemporal capital asset pricing model. Econometrica, 41, 867-887.

Merton, R. C. (1980) On estimating the expected return on the market: an exploratory investigation. Journal of Financial Economics, 8, 323-361.

Meyerhoff, N. J. (1978) The influence of Daylight Saving Time upon motor vehicle fatal traffic accidents. Accident Analysis and Prevention, 10, 207-221.

Monk, T. H. (1980) Traffic accident increases as a possible indicant of desynchronosis. Chronobiologia, 7, 527-529. 
Moorcroft, W. H., \& Belcher, P. (2003) Understanding sleep and dreaming. New York: Plenum.

Mossin, J. (1966) Equilibrium in a capital asset market. Econometrica, 34, 768-783.

National Sleep Foundation. (2001) Sleep in America poll: 2001. Washington, DC: Author.

Nelson, D. B. (1991) Conditional heteroskedasticity in asset returns: a new approach. Econometrica, 59, 347-370.

O'Brien, E. M., \& Mindell, J. A. (2005) Sleep and risk-taking behavior in adolescents. Behavioral Sleep Medicine, 3, 113-133.

Osborne, M. F. M. (1962) Periodic structure in the Brownian motion of the stock markets. Operations Research, 10, 345-379.

PAGAN, A. (1984) Econometric issues in the analysis of regressions with generated regressors. International Economic Review, 25, 221-247.

Pagan, A. R., \& Ullah, A. (1988) The econometric analysis models with risk terms. Journal of Applied Econometrics, 3, 87-105.

Pinegar, J. M. (2002) Losing sleep at the market: a comment. American Economic Review, 2, 1251-1256.

ScrugGS, J. T. (1998) Resolving the puzzling intertemporal relation between the market risk premium and conditional market variance: a two-factor approach. Journal of Finance, 53, 575-603.

Sharpe, W. F. (1964) Capital asset prices: a theory of market equilibrium under conditions of risk. Journal of Finance, 19, 425-442.

Varughese, J., \& Allen, R. P. (2001) Fatal accidents following changes in Daylight Savings Time: the American experience. Sleep Medicine, 2, 31-36.

Woodridge, J. M. (2009) Intorductory econometrics: a modern approach. (4th ed.) Mason, $\mathrm{OH}$ : South-Western.

Worthington, A. (2003) Losing sleep at the market: an empirical note on the Daylight Saving anomaly in Australia. Discussion Papers in Economics, Finance, and International Competitiveness, No. 146, Queensland University of Technology.

Yu, J. (2005) On a leverage in a stochastic volatility model. Journal of Econometrics, 127, 165-178.

Accepted November 21, 2011. 